\title{
Squamous Gell Barcinoma in Background of Chronic Lymphedema Secondary to Filariasis: A Rare Entity
}

\author{
Sanjeev Kumar, Shefali Gautam', Sanchit Mittal, Anand Kumar Mishra \\ From the Department of General Surgery and Department of Anaesthesiology', \\ King George's Medical University, Lucknow, Uttar Pradesh, India.
}

\begin{abstract}
:
Filariasis, a parasitic infection caused by Wuchereria brancrofti, is common in Northern India and most common cause of secondary lymphedema. Dreaded complication of chronic lymphedema is lymphangiosarcoma. In our case, prolonged standing elephantiasis for about 2 decades leads to development of squamous cell carcinoma. Squamous cell carcinoma is a potentially lethal entity and awareness of association can lead to early intervention. We will discuss the management and possible pathogenesis of this unusual case.
\end{abstract}

Key words: Filariasis, Elephantiasis, Squamous Cell Carcinoma, Ulcer, Lymphedema, Lymphangiosarcoma.

\section{Introduction}

Filarial lymphedema is a known entity involving lower limbs. Malignant changes which can arise in a chronic lymphedema include Kaposi's sarcoma, melanoma, lymphoma, malignant fibrous histiocytoma on squamous cell carcinoma. The association with squamous cell carcinoma have been noted in chronic lymphedemtous limb with additional factors for carcinogenesis. In our case, we found no additional risk factor except for chronic filarial lymphedema. Squamous cell carcinoma in a patient with elephantiasis developed after 18 years with no additional risk factors is described here.

\section{Case Report}

A 65 year old male resident belonging to rural background of Uttar Pradesh presented with swelling of left lower limb extending upto knee joint with off and on multiple ulcerative lesions since 18 years. Patient had fever with chills eighteen years back following which he developed edema of left lower limb. He developed multiple abscesses in left leg (2 years back) for which incision and drainage was done at a private hospital. He was managed with dressing, antibiotics according to culture sensitivity, antifilarial and anti-inflammatory drugs for varying duration of 1 month but no improvement was noted. Later on, he developed non healing ulcers at various places besides incision. Seven months back an ulcer was excised at a district hospital, however histopathology was not done.

Patient presented to our hospital with multiple foul smelling ulcerative lesions over left leg,

Corresponding Author: Dr. Sanjeev Kumar

Email: drsanjeevkgmc@gmail.com

Received: October 5, 2013 | Accepted: December 17, 2013 | Published Online: December 25, 2013 This is an Open Access article distributed under the terms of the Creative Commons Attribution License (creativecommons.org/licenses/by/3.0)

Conflict of interest: None declared | Source of funding: Nil | DOl: http://dx.doi.org/10.17659/01.2013.0107 
fever without rigors, sepsis and loss of appetite. Examination revealed febrile normotensive patient with pallor who was unable to stand or walk [Fig.1]. Examination of left leg revealed non pitting edema till knee joint with multiple ulcers having everted edges, foul smelling discharge, yellowish base and surrounding hyperaemia. Ulcers were non tender and bleeding on touch.

Routine haematological and biochemical investigations were within normal limits expect pus culture which revealed Proteus mirabilis. Ultrasound Doppler was within normal limits while $X$ ray of lower limb did not reveal any bony abnormality. He was initially managed with broad spectrum intravenous antibiotics, dressing with saline after washing with $20 \%$ strength hydrogen peroxide and limb elevation. No clinical improvement was seen with antibiotics, however fever and tenderness subsided. Histopathology of ulcer margin was consistent with moderately differentiated squamous cell carcinoma. Patient was planned for above knee amputation with inguinal lymph node dissection. Post-operative period was uneventful [Fig.2]. Final histopathology of limb was consistent with multifocal invasive squamous cell carcinoma, large cell keratinising type, moderately to poorly differentiated with clear margins and tumour invasion upto subcutaneous fat. Left inguinal lymph nodes showed metastatic deposits from squamous cell carcinoma which was large cell keratinizing type and well differentiated. Further patient was planned for loco-regional radiation as suggested by radiotherapist. He has been also referred for artificial limb.

\section{Discussion}

Filariasis is caused by microfilaria of Wuchereria brancofti which obstruct lymphatic flow causing lymphedema [1]. Malignant changes which can arise in chronic lymphedema include Kaposi's sarcoma, melanoma, lymphoma, malignant fibrous
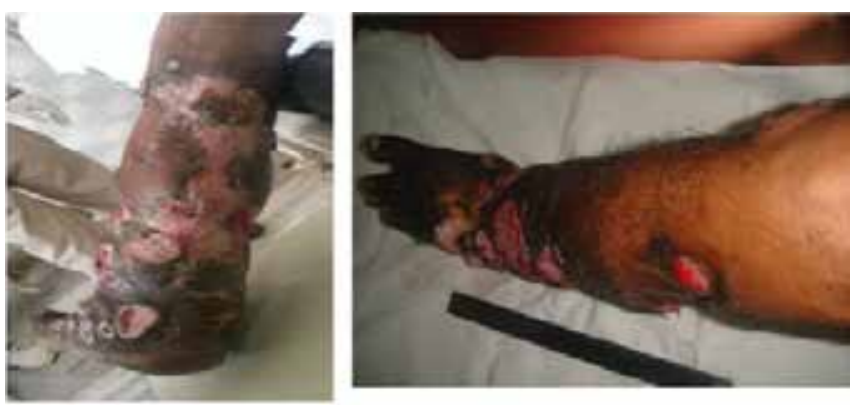

Fig.1: Multiple ulcers in filarial limb made patient unable to stand and walk.

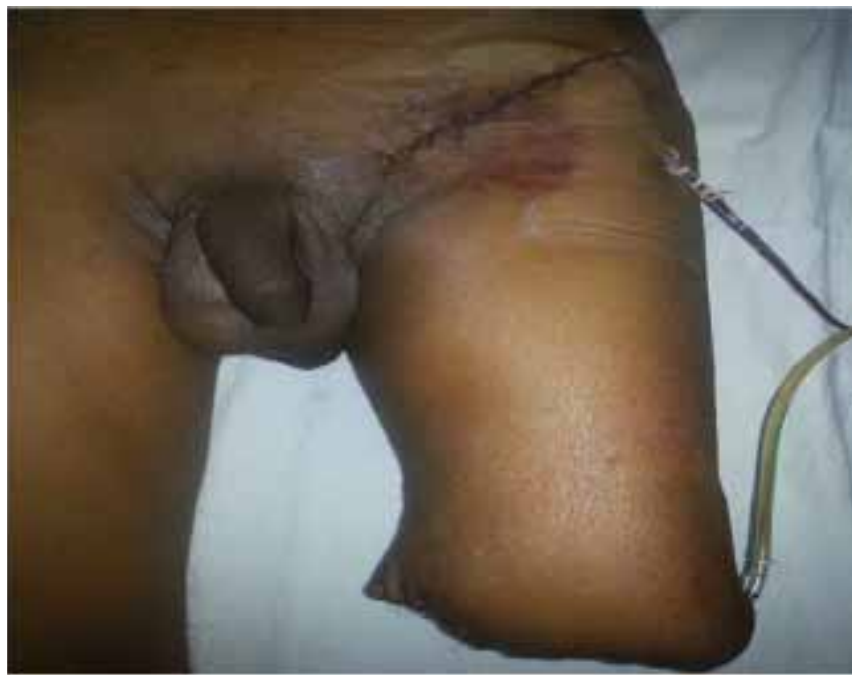

Fig.2: Post operative above knee amputated left lower limb.

histiocytoma, and squamous cell carcinoma [2]. Chronic lymphedema causes extrusion of protein into interstitial space with influx of inflammatory mediators. One of the proposed hypotheses for development of malignancy is chronic inflammation; infection is secondary to translocation of bacteria into edematous tissue [3]. Chronic lymphedema causes lymphangiosarcoma [3] but squamous cell carcinoma (SCC) has been rarely reported. Squamous cell carcinoma is an aggressive tumor and precaution must be taken in patients with chronic lymphedema to prevent ulceration which predispose to malignant transformation. 
Majority of cases of SCC are seen in the limbs $[4,5]$. Most of the theories on carcinogenesis in lymphedema centre on immunological factors. It is believed that the deficiency in afferent lymphatic drainage prevents early recognition of the tumorspecific antigen [6]. A field change theory has been proposed suggesting that in some a chronic lymphedema promote carcinogenesis [7]. Our case illustrates the need for careful evaluation and follow-up of patients with chronic lymphedema. In practical terms, the potential for malignant growth in the lymphedematous tissue should be borne in mind. Patients developing non healing ulcer in lymphedematous limb should undergo ulcer margin biopsy. Chronic warty hyperkeratosis and fissuring may hide a lesion leading to delay in the presentation of a malignant ulcer. A dermatological opinion should be taken as and when necessary. Finally, the link between these two rare conditions should be remembered.

In SCC, an antigen has been described. SCC antigen may be involved in the malignant behavior of squamous cell cancers, functioning in invasion and/ or metastasis. Consequently, serum concentrations of squamous cell carcinoma antigen can be used to monitor various squamous cell carcinomas. Associations between serum squamous cell carcinoma antigen concentrations and tumor stage, size, and progression have also been observed. So, squamous cell carcinoma antigen could play an essential role in surveillance of these difficult cases $[8,9]$.

\section{Conclusion}

In practical terms, the potential for malignant growth in the lymphedematous tissue should be borne in mind. Patients should be instructed on good hygiene and regular monitoring of any affected area. Any new or suspicious growth in chronic lymphedenomatous limb should be examined and biopsied without delay.

\section{References}

1. Shenoy RK. Clinical and Pathological Aspects of Filarial Lymphedema and Its Management. Korean J Parasitol. 2008;46:1 19-125.

2. Lister RK, Black MM, Calonje E, Burnand KG. Squamous cell carcinoma arising in chronic lymphoedema. British Journal of Dermatology. 1997;136:384-387.

3. Muller R, Hajdu SI, Brennan MF. Lymphangiosarcoma associated with chronic filarial lymphedema. Cancer. 1987;59(1):179183.

4. Furukawa $H$, Yamamoto $Y$, Minakawa $H$, Sugihara T. Squamous cell carcinoma in chronic lymphedema: case report and review of the literature. Dermatol Surg. 2002;28:951-953.

5. Shivakumar T, Nair SV. Delayed Contralateral Intra-Parotid Nodal Metastasis from an Oral Squamous Cell Carcinoma. Journal of Case Reports. 2013;3(2):317-321.

6. Futrell JW, Myers GH Jr. Regional lymphatics and cancer immunity. Ann Surg. 1973;177:1-7.

7. Abhyankar SV, Kulkarni A, Kulkarni M, Agarwal NK. Squamous cell carcinoma of the penis and scrotum in a patient with chronic scrotal and penile lymphedema. Indian J Dermatol. 2010;55(4):387-389.

8. Laniado ME, Lowdell C, Mitchell H, Christmas TJ. Squamous cell carcinoma antigen: a role in the early identification of nodal metastases in men with squamous cell carcinoma of the penis. BJU Int. 2003;92:248-250.

9. Kommu S, Hadway P, Watkin N. Squamous cell carcinoma antigen as a biomarker for penile cancer. BJU Int. 2005;95:478-479. 